symptoms were: delay in the onset of oestrus, low conception rates, abortion without any clinical signs, as well as possible repercussions on the health of the piglets. In the herds studied, the programme established to improve the performance was mainly based on a increase in the level of feed intake. Application of this programme led to disappearance of the various disturbances and to an improvement of the performance. These results show that the feeding level has to be adjusted to the requirements of each animal in each herd. Occurrence of severe disorders may be prevented by a steady control of some important parameters in the breeding sow.

\title{
Vitamin $D$ deficiency in the pig
}

\section{A. POINTILLART}

\author{
I.N.R.A., Station de Recherches de Nutrition \\ 78350 Jouy-en-Josas (Fratice)
}

Consequences of vitamine D deficiency on calcaemia, phosphataemia, 25 hydroxycholecalciferol (25-OH-D $\mathrm{D}^{3}$ ) parathyroid hormone (PTH), calcitonin (CT), phosphatasemia, urinary hydroxyproline, intestinal calcium binding proteins (CaBP), bone mineral content (BMC) and histological bone findings were studied in 50 growing pios. In the first experiment, plasma Ca, P. PTH and CT kinetics were followed during one month. At slaughter, intestinal CaBP and plasma $25-\mathrm{OH}-\mathrm{D}^{3}$ were measured either in vitamin D-deficient pigs or in healthy ones. In a second experiment, the effects on bone and plasma criteria of vitamin $D^{3}$ and vitamin $D^{3}$ sulfoconjugate $\left(\mathrm{SD}^{3}\right)$ were compared over a 50-day $\mathrm{D}$-deficiency period. In a third experiment, bilateral nephrectomy was done in 5 pigs to observe the effect of a lack of 1.25 dihydroxycholecalciferol (I.25 DHCC) synthesis on plasma PTH.

Bone criteria such as density, cortical thickness, X-ray pictures were better D-deficiency indicators than BMC or plasma mineral levels. Plasma analysis never reflected accurately D-deficiency iıtensity, even if hypocalcaemia, hypophosphataemia, increased PTH and decreased CT concentrations in the plasma appeared in some, but not all cases. A 3-month D-deficiency caused a very large decrement of $25-\mathrm{OH}-\mathrm{D}^{3}$ and correlatively a decrease in intestinal CaBP. Vitamin $\mathrm{D}^{3}$ as $\mathrm{SD}^{3}$ (Ioo IU/day) restored the plasma $25-\mathrm{OH}-\mathrm{D}^{3}$ to normal levels, but did not change plasma $\mathrm{PTH}, \mathrm{Ca}, \mathrm{P}$, or phosphatase concentrations or urinary hydroxyproline. Vitamin $\mathrm{D}^{3}$ was more effective on bone than $\mathrm{SD}^{3}$.

In binephrectomized pigs, hyperparathyroidism appeared after 2 days, but not concomitantly with hypocalcaemia which became apparent I day later.

The relative interest of plasma and bone parameters is discussed in relation to D-deficiency search for suitable indicators, and determination of the parameters used to determine vitamin-D requirement. Hormonal regulation of plasma $\mathrm{Ca}$ pigs is examined with special emphasis on P'TH-1.25 DHCC interaction. Poor P'IH reactions in relation to more sensitive variations of C'T and occasional hypomagneasemia are mentioned.

\section{Rectal prolapse in sows. Influence of pelvis conformation determined by goniometry}

\author{
M. Y. LE BRET \\ Ministère de l'Agriculture, Direction de la Qualité, Services Vétérinaires \\ Station de Pathologie Porcine, B.P. no 9, 22440 Ploufragan (France)
}

In five pig herds, sows of the same origin suffered from rectal prolapse at farrowing. These sows were characterized by a particular pelvic conformation shown by measuring different angles of the pelvis. The measur? of the angle between the coccygeae vertebrae and the pelvis appeared to be the best means to reveal the predisposition of sows to rectal prolapse: the larger the angle 
the greater the risks of prolapse. The author explains the mechanism of prolapse development by the particular position of the sacrosciatic ligament and its looseness at the time of farrowing. This measure is suggested as a means for determining whether a sow should be culled or not.

\title{
Unknown epidemiological aspects of classical swine fever. Consequences on prophylaxis
}

\author{
P. VANNIER (1), E. PLATEAU (2), J. P. TILLON (1) \\ (1) Ministère de l'Agriculture, Direction de la Qualité, Services Vétérinaives \\ Station de Pathologie Porcine, B.P. 9, 22440 Ploufragan (France) \\ (2) Laboratoire Central de Recherches Vétérinaires \\ 22, rue Pierre-Curie, B.P. no 67, 94703 Maisons-Alfort Cedex (France)
}

Two different experiments were carried out with a particular strain of swine fever virus solated from a field case. First, post weaning piglets were infected through the intra muscular toute. Individual susceptibility was prominent in the development of clinical signs and the severity of the disease among post weaning piglets. Duration of hyperthemia ranged from one to nineteen days; $4^{\circ} \mathrm{p}$. I 00 of the animals died, but the survivors were only slightly affected in their final growth rate.

Survivors did not excret the virus more than $26 / 30$ days after inoculation and the virus was not detected in the organs of the animals after slaughter 60 days post infection and later. On the other hand sows were inoculated at different stages of pregnancy with the same strain; no clinical sign was observed in the sows after inoculation and during pregnancy, but a high proportion of piglets exhibited splay-leg, nervous disorders and perinatal mortality. A few piglets from sows inoculated during pregnancy survived and remained inapparent carriers of virus during their whole life without producing antibodies. It was concluded that immunotolerance had been induced in these animals. Transmission of the virus from immunotolerant to susceptible pigs was made by contact five weeks after farrowing, but not after three months in spite of the persistance of the virus at a high concentration in the blood and organs of immunotolerant pigs. These results could explain the appearance on the field of some variantes of the disease and the presence of cases of unknown origin and unexplained epidemiological factors. These particularities and the measures of sanitary prophylaxis necessary for the eradication of the disease are discussed.

\section{I.N.R.A. \\ Epidemiology of pig diseases in connection with intensive production system

\author{
J. P. TILLON \\ Ministère de l'Agriculture, Direction de la Qualité, Services Vétérinaires \\ Station de Pathologie Porcine, B.P. no 9, 22440 Ploufragan (France)
}

\begin{abstract}
After a description of the main pathological cases in connection with intensive pig production, the author describes the modern environmental conditions of pig herds with a special reference to the overall management and productivity imperatives. The pathological manifestations observed should not be interpreted independently as they result from an inadaptation of rearing conditions to production goals. The intervention of the pathologist should therefore lead to a correction of overall management failures. The establishment of a valid " herd diagnosis " requires a co-operation between the pathologist and the other pig production specialists. The development of health control systems is considered.
\end{abstract}

